\title{
CASA EN TIERRA AJENA. UN DOCUMENTAL SOBRE MIGRACIÓN FORZADA EN AMÉRICA CENTRAL. PRODUCCIÓN: IVANNIA VILLALOBOS VINDAS Y CARLOS SANDOVAL GARCÍA. DIRECCIÓN: IVANNIA VILLALOBOS VINDAS. BASADO EN EL LIBRO NO MÁS MUROS. EXCLUSIÓN Y MIGRACIÓN FORZADA EN CENTROAMÉRICA DE CARLOS SANDOVAL GARCÍA. COSTA RICA: UCR-UNED-CONARE, 2016, 80 MIN.
}

Florencia Quesada Avendaño

Recibido: 29/06/2017 Aceptado: 07/07/2017

Cuando me vine de mi tierra El Salvador, con la intención de llegar a Estados Unidos, sabía que necesitaría más que valor, sabía que a lo mejor quedaba en el camino. Son tres fronteras las que tuve que cruzar, por tres países anduve indocumentado, tres veces tuve yo la vida que arriesgar, por eso dicen que soy tres veces mojado.

Extracto del corrido "Tres Veces Mojado" Los Tigres del Norte

\section{La valentía y el dolor de un pueblo que camina}

Desde hace muchas décadas, y especialmente provenientes del llamado Triángulo Norte (Guatemala, El Salvador y Honduras), miles de centroamericanos pobres migran intentando llegar a los Estados Unidos. La migración forzada en Centroamérica -de un 10 a un 12 por ciento de la población- es uno de los dramas humanitarios más desoladores e invisibilizados que enfrenta la región.

¿Por qué migran los centroamericanos a pesar de lo arriesgado y peligroso del viaje? Las causas históricas, razones estructurales de la violencia y desigualdad, los sueños y dolores de los migrantes, la criminalización de la migración y la infraestructura de solidaridad para ayudar a los migrantes, son algunos de los temas centrales 
analizados en el documental Casa en Tierra Ajena, coproducido por la Universidad Estatal a Distancia (UNED) y la Universidad de Costa Rica (UCR) y financiado a través de los fondos del Consejo Nacional de Rectores (CONARE).

A manera de un road-movie de horror e injusticias, el documental nos transporta por parajes desolados, ríos, estaciones de buses, líneas y vagones del ferrocarril de la llamada "Bestia" -el ferrocarril de carga mexicano- principal medio de transporte clandestino de los migrantes centroamericanos. Villalobos y Sandoval presentan de manera clara y fehaciente cómo los migrantes son doblemente víctimas. Primero, de un sistema que los olvidó y no les ofrece la más mínima posibilidad de salir del círculo de pobreza, marginación y violencia. Los migrantes son seres humanos "invisibles", como bien lo definió el sacerdote director de la Casa del Migrante. Migrar es la única opción para escapar de la violencia estructural y la falta de oportunidades. Al hacerlo son tratados como "delincuentes", sin derechos, nuevamente vulnerables. Y segundo, son víctimas (en especial las mujeres), y tienen que enfrentar a una diversidad de mafias (carteles de la droga, policías locales, autoridades de migración), las cuales dominan las rutas por donde transitan en su paso por México, y, ante los cuales, no siempre sobreviven. Quienes topan con "suerte", cruzarán la frontera e intentarán hacer una nueva vida (antes de que sean, de nuevo, atrapados y deportados a sus países de origen). Sin embargo, la mayoría queda en el camino, muchas veces mutilados, física y mentalmente, por las experiencias traumáticas de las que han sido víctimas.

Para comprender el fenómeno migratorio centroamericano desde sus raíces, en el contexto nacional, regional e internacional, como acertadamente lo demuestran Villalobos y Sandoval, es necesario analizarlo con una mirada de larga duración, para entender la multiplicidad de factores históricos y estructurales que han dado como resultado la formación de sociedades tan desiguales, injustas y violentas; que obligan a miles de centroamericanos a emprender un viaje tan macabro. El documental se divide en tres partes:

a) Causas y razones de la migración a través de estudios de casos en Guatemala (Ixcán, Huhuetenango, San José del Golfo), El Salvador y Honduras (Bajo Aguán y Barra Vieja).

b) Criminalización de los migrantes en territorio mexicano.

c) Casas de migrantes como centros de esperanzas.

La condena por genocidio y crímenes de lesa humanidad al ex dictador Efraín Ríos Montt en el 2013 (debido a las atrocidades cometidas en la región maya Ixil de Ixcán), abre el análisis de los diversos estudios de casos, centrados en el Triángulo Norte. En Guatemala, el 83 por ciento de las víctimas por violaciones a los derechos humanos durante la Guerra Civil (que se prolongó durante 36 años) correspondió a poblaciones mayas. 
El juicio contra Ríos Montt, ${ }^{1}$ clave y emblemático -por primera vez se juzgó a un expresidente por genocidio en una corte nacional-, fue anulado por la Corte de Constitucionalidad Guatemalteca unas semanas después, la impunidad ha sido siempre total. Durante el enfrentamiento armado, y para combatir a las guerrillas, el Estado y los militares guatemaltecos utilizaron la estrategia conocida como tierra arrasada, que dio como resultado la muerte de doscientos mil personas, la desaparición de cincuenta mil más, y un saldo de un millón de refugiados en México. Comunidades indígenas enteras fueron literalmente borradas del mapa, sus poblaciones desplazadas y desestructuradas. ${ }^{2}$

En El Salvador, la historia se repite, marcada por el asesinato de Monseñor Óscar Arnulfo Romero (1917-1980) y el inicio de la Guerra Civil, que dejó como saldo 70000 salvadoreños asesinados (la mayoría civiles). Las víctimas del conflicto armado se cuentan por miles en monumentos, los nombres de los muertos grabados en piedra al menos para recordarlos de manera simbólica; la impunidad también ha sido absoluta. En el caso de El Salvador con altos índices de migración desde el período de las guerras civiles, el documental se enfoca en la violencia urbana actual a través de la Maras (pandillas urbanas), su origen y repercusiones, la mejor expresión de una exclusión estructural.

En Honduras se analiza el Bajo Aguán, al noreste y Barra Vieja en el Caribe. En ambos casos, las empobrecidas comunidades tienen altas tasas de migración directamente relacionadas con el despojo de sus tierras y la falta de oportunidades. En el Bajo Aguán, luego de la Ley de Modernización Agrícola aprobada en la década de 1990 durante la presidencia de Rafael Leonardo Callejas, la tierra fue vendida a tres grandes transnacionales para la producción de palma aceitera El caso de Barra Vieja, ligado al desarrollo turístico, es necesario entenderlo en el contexto global del desarrollo del turismo costero. Este desarrollo a gran escala en Centroamérica ha llevado a procesos de privatización y concentración de la tierra. En este caso, la propiedad comunal ancestral de las comunidades garífunas fue privatizada por el Estado. Las zonas costeras del Caribe, que fueron históricamente aisladas y pobladas por Garífunas -en el caso de Honduras y Nicaragua-, en las últimas décadas se han convertido en regiones codiciadas para el desarrollo de mega proyectos turísticos con capital transnacional para un turismo exclusivo como en el caso de Indura Beach and Golf Resort en la bahía de Tela.

Nuevamente, las comunidades se ven desplazadas en procesos desiguales, violentos y traumáticos. En Barra Vieja, un sector de la comunidad ha luchado para poder preservar su tierra y formas de vida (derecho a la pesca y al agua), a través de la Organización Fraternal Negra Hondureña (OFRANEH). No obstante, para muchos jóvenes la migración se convierte en la única alternativa. En síntesis, el denominador común en todos los casos analizados es el despojo de las tierras en las poblaciones rurales mediante sistemas violentos y coercitivos; pero, al mismo tiempo, la resistencia y valentía de las comunidades en defensa de la tierra. 
Guatemala, Honduras y El Salvador se encuentran entre los países más desiguales de América Latina (la región más disímil en el mundo). ${ }^{3}$ Las oposiciones se acrecentaron durante la década de implementación del modelo neoliberal en el istmo. Una mayoría empobrecida y completamente marginalizada y del otro lado del espectro una élite oligárquica cada vez más rica.

Otro de los diversos aportes del documental se refiere al análisis de cómo se ha llevado a cabo un proceso de "criminalización" de los migrantes, por parte del Gobierno mexicano y gracias al financiamiento del Gobierno de Estados Unidos (compra de equipos, personal y transporte). ¡Actualmente existen 53 centros de detención en México, en un país con 32 Estados! Estos lugares -en la práctica prisiones sin derechos- son un nuevo espacio en donde los migrantes se encuentran en un total estado de indefensión y vulnerabilidad.

Aunque sobre la migración en Centroamérica se han producido infinidad de reportajes, documentales y películas, la originalidad y fuerza de Casa en Tierra Ajena, entre muchas de sus virtudes, consiste en mostrarnos la importancia de la solidaridad humana y de la esperanza. Ante la pobreza, la adversidad, la injusticia, siempre existen colectivos, héroes anónimos que saben tender una mano y ayudar a los que más lo necesitan. El documental cierra el análisis con ese lado humano y solidario ejemplificado en las Casas del Migrante en México. Estos sitios de acogida temporal, fundados y administrados por organizaciones religiosas, sobreviven gracias al apoyo de las iglesias y las donaciones de las comunidades; los sectores más pobres ayudan con lo poco que tienen.

Las Casas del Migrante, literales oasis de esperanza, son centros de apoyo (material, físico y psicológico, pero también de denuncia y de preservación de la memoria histórica de las víctimas). Surgieron en el último tramo del trayecto para resolver un problema social, en una de las zonas de mayor violencia contra los migrantes. Un problema al que los Estados de la región involucrados han dado la espalda e ignorado.

Casa en Tierra Ajena, basado en una excelente investigación de base sobre la migración en Centroamérica, es testimonio del poder de las imágenes y de la importancia de unir esfuerzos y recursos institucionales para producir un material documental de primera calidad, para llegar a un público más amplio; y así conocer y comprender el rostro humano y de esperanza de un problema doloroso y central, pero de muchas maneras invisibilizado en Centroamérica.

Gracias a Casa en Tierra Ajena, los migrantes se han convertido en un ejemplo de perseverancia y lucha ante la adversidad (y no criminales-clandestinos como los ha estigmatizado el sistema). Como bien lo anota al final del documental Artemio Velasco, de la Casa del Migrante en Saltillo, Estado de Coahuila:

Yo siento un ejemplo que me dan de ellos, verlos avanzar y ahí van y no se detienen. Y para mí de verdad es admirable este pueblo que camina. 


\section{Notas}

1 MINUGUA. Informe Final Misión de Verificación de las Naciones Unidas en Guatemala. Guatemala, 15 de noviembre de 2004, p. 4. Recuperado de http://www.derechoshumanos.net/lesahumanidad/ informes/guatemala/Informe-Final-Minugua.pdf

2 Para un interesante reportaje visual de estos pueblos arrasados ver Oscar Farfán. Guatemala: Tierra Arrasada. Recuperado de http://www.gatopardo.com/reportajes/guatemala-tierraarrasada/

3 CEPAL (Comisión Económica para América Latina y el Caribe. Panorama Social de América Latina, 2016. Naciones Unidas, S1700178_es.pdf. Recuperado de http://www.cepal.org/es/ publicaciones/41598-panorama-social-a merica-latina-2016-documento-infor mativo

Florencia Quesada Avendaño. Costarricense, obtuvo su doctorado en Estudios Latinoamericanos por la Universidad de Helsinki, Finlandia. Se desempeña como investigadora y profesora en el Helsinki Collegium for Advanced Studies de la Universidad de Helsinki. Además, es profesora adjunta en Estudios Latinoamericanos y Estudios de Desarrollo ambos en la Universidad de Helsinki. Es autora de varios libros, el último La Modernización entre Cafetales. San José, Costa Rica, 1880-1930 (2011), que obtuvo el premio Cleto González Víquez de la Academia de Geografía e Historia en el 2011.

Contacto: florencia.quesada@helsinki.fi

ORCID: 0000-0002-5497-4009 
